\title{
Post-orthodontic retention: how much do people deciding on a future orthodontic treatment know and what do they expect? A questionnaire-based survey
}

\author{
Lasance, Sandrine Janine ; Papageorgiou, Spyridon N ; Eliades, Theodore ; Patcas, Raphael
}

\begin{abstract}
OBJECTIVE This cross-sectional study aimed to explore the level of knowledge and expectations people deciding on a future orthodontic treatment have about post-orthodontic retention and to investigate the influence of sociocultural characteristics. MATERIAL AND METHODS A total of 227 consecutive people involved as legal decision maker (as patient, parent, or legal guardian) for a prospective orthodontic treatment (mean age 37.1 years; 37.3 per cent male) received before their first appointment a questionnaire to assess their knowledge and expectations about post-orthodontic retention. Data were analysed descriptively, whereas predictors were identified with logistic regressions at $\mathrm{P}$ value of less than or equal to 0.05 . RESULTS Among the 220 responders, 46.3 per cent $(\mathrm{n}=99)$ knew that retention appliances are used after orthodontic treatment and 52.8 per cent $(\mathrm{n}$ $=113)$ believed perfect results can guarantee stability, whereas at the same time, 77.8 per cent $(n=168) \mathrm{knew}$ that teeth can move on their own without any orthodontic appliances. The majority considered stability of the orthodontic result important or extremely important ( 94.5 per cent; $n=206$ ), preferred bonded over removable retainers (67.2 per cent; $\mathrm{n}=133)$, believed the orthodontist to be primarily responsible for a stable result $(73.2$ per cent; $n=158$ ), and found it appropriate to charge for recall visits (72.9 per cent; $n=153$ ). Participants' gender, age, education, nationality, and past orthodontic experiences within the close family significantly influenced answers. LIMITATIONS The setting of a single-centred survey conducted in one university moderates the generalizability of the portrayed results. CONCLUSIONS Although stability of orthodontic treatment results is very important to people deciding about a prospective orthodontic treatment, knowledge regarding the need for post-orthodontic retention varies and may at times be contradictious. Sociocultural factors seem to influence the level of knowledge and the expectations on post-orthodontic retention.
\end{abstract}

DOI: https://doi.org/10.1093/ejo/cjz023

Posted at the Zurich Open Repository and Archive, University of Zurich

ZORA URL: https://doi.org/10.5167/uzh-194586

Journal Article

Accepted Version

Originally published at:

Lasance, Sandrine Janine; Papageorgiou, Spyridon N; Eliades, Theodore; Patcas, Raphael (2020). Post-orthodontic retention: how much do people deciding on a future orthodontic treatment know and what do they expect? A questionnaire-based survey. European Journal of Orthodontics, 42(1):86-92.

DOI: https://doi.org/10.1093/ejo/cjz023 


\section{Post-orthodontic retention: How much do people enrolled for orthodontic treatment know and what do they expect? A questionnaire-based survey}

Sandrine J. Lasance, ${ }^{1}$ Spyridon N. Papageorgiou, ${ }^{1}$ Theodore Eliades, ${ }^{1}$ Raphael Patcas ${ }^{1}$

1 Clinic of Orthodontics and Pediatric Dentistry, Center of Dental Medicine, University of Zurich, Plattenstrasse 11, 8032 Zurich, Switzerland

Corresponding author: Dr. med. dent. Raphael Patcas, PhD, Clinic of Orthodontics and Pediatric Dentistry, Center of Dental Medicine, University of Zurich, Plattenstrasse 11, 8032 Zurich, Switzerland; raphael.patcas@zzm.uzh.ch.

Short title: Patient expectations on orthodontic retention

Keywords: orthodontics; retention; patient satisfaction; survey; questionnaire

ORCIDs

Sandrine J. Lasance: -

Spyridon N. Papageorgiou: 0000-0003-1968-3326

Theodore Eliades: 0000-0003-2313-4979

Raphael Patcas: 0000-0003-3906-9083 sandrinejanine.lasance@uzh.ch

spyridon.papageorgiou@zzm.uzh.ch

theodore.Eliades@zzm.uzh.ch

raphael.patcas@zzm.uzh.ch

Conflict of interest: None.

Words in abstract: 247 / 250

Words in text: 3827 / 5000 


\section{Post-orthodontic retention: How much do people enrolled for orthodontic treatment know and what do they expect? A questionnaire-based survey}

\section{Summary}

Objective: This cross-sectional study aimed to explore the level of knowledge and expectations prospective orthodontic patients have about post-orthodontic retention, and to investigate the influence of socio-cultural characteristics.

Material and methods: A total of 227 consecutive people involved as legal decision maker (as patient, parent, or legal guardian) for a prospective orthodontic treatment (mean age 37.1 years; $37.3 \%$ male) received prior to their first appointment a questionnaire to assess their knowledge and expectations about post-orthodontic retention. Data were analysed descriptively, while predictors were identified with logistic regressions at $p \leq 0.05$.

Results: Among the 220 responders, 46.3\% (n=99) knew that retention appliances are used after orthodontic treatment and $52.8 \%(n=113)$ believed perfect results can guarantee stability, while at the same time $77.8 \%(n=168)$ knew that teeth can move on their own without any orthodontic appliances. The majority considered stability of the orthodontic result important or extremely important $(94.5 \% ; n=206)$, preferred bonded over removable retainers $(67.2 \% ; n=133)$, believed the orthodontist to be primarily responsible for a stable result $(73.2 \% ; n=158)$, and found it appropriate to charge for recall visits $(72.9 \% ; n=153)$. Participants' sex, age, education, nationality, and past orthodontic experiences within the close family significantly influenced answers.

Limitations: The setting of a single-centred survey conducted in one university moderates the generalisability of the portrayed results.

Conclusions: Although stability of orthodontic treatment results is very important to people deciding about a prospective orthodontic treatment, knowledge regarding the need for post-orthodontic retention varies and may at times be contradictious. Socio-cultural factors seem to influence the level of knowledge and the expectations on post-orthodontic retention. 


\section{MANUSCRIPT}

\section{Introduction}

The significance of retaining tooth alignment after orthodontic treatment to prevent relapse was identified as early as 1904 (1), and its clinical importance has been emphasised since the 1980s-1990s (1-5). While it has become an undisputed fact that orthodontic patients are in need of some type of physical retention of the achieved tooth movement after completion of treatment, orthodontists still debate about the benefits and drawbacks of different retention appliances and protocols (6).

Several studies have been performed over the last years aiming to assess the level of knowledge or the prevailing preferences of dentists and orthodontists in particular, concerning orthodontic retention. These surveys have been conducted in numerous countries, including Australia (7), Ireland (8), Lithuania (5), Malaysia (9), the Netherlands (10, 11), New Zealand (7), Saudi Arabia (12), Switzerland (13-15), the United Kingdom (16), the United States of America (17-19), and Norway (20), and have all contributed to the current understanding of how orthodontic retention is being approached by clinicians.

In stark contrast to the established evidence of the orthodontists' level of knowledge and preferences in orthodontic retention, far less is known about prospective patients' concerns, expectations and level of knowledge in this field. Several studies have assessed patients' expectations on orthodontic treatment in general (21), but orthodontic retention per se has apparently never been subject of any scientific investigation.

The seeming paucity of evidence regarding prospective patients' awareness of post-orthodontic retention issues is disturbing. The necessity to understand the expectations and assess the level of knowledge of people interested in an orthodontic treatment is accentuated by the fact that post-orthodontic satisfaction is strongly related to the patients' perception of tooth stability and responsibilities during the retention phase (22).

The primary aim of this study was therefore to assess the level of knowledge and the expectations concerning post-orthodontic retention of people enrolled for an orthodontic treatment, prior to their first appointment. The secondary aim was to discern whether demographic and socio-cultural characteristics of the participants influence their level of knowledge and their expectations. 


\section{Material and methods}

\section{Ethics approval}

Ethical approval for this anonymised questionnaire survey was obtained from the local ethics committee of the responsible governmental body (BASEC-Nr. Req-2017-00502).

\section{Study design and participants}

A self-developed and anonymised questionnaire was distributed to patients enrolled for their first appointment at the Clinic of Orthodontics and Pediatric Dentistry at the Center of Dental Medicine of the local university. Prior to their first appointment, a paper-and-pencil questionnaire was handed out consecutively to patients (non-selective process) by a dental assistant not involved in the study, to be filled anonymously in the waiting area. All participants were briefed about the goal of this survey, its voluntary basis, and its anonymised design. The participants were instructed to fill out the questionnaire silently and independently, without time restriction. According to legal doctrine (23), patients younger than 16 years of age are not considered to have acquired the ability to reach rational decisions for complex or prolonged medical treatment, and therefore in such cases the person acting as legal decision maker (usually the parent or legal guardian of the patient) was instructed to fill out the questionnaire.

The questionnaire consisted of three sections of closed-ended queries (Table 1): (a) items relating to participant demographical and socio-cultural characteristics, (b) items concerning the participant's knowledge about post-orthodontic retention need, and (c) items focusing on the participant's attitude and expectations towards orthodontic retention. The questionnaire was piloted prior to the start of the study with 10 people of different age and background to ensure comprehensibility. Piloting the survey was specifically done to identify items that lack clarity. After evaluation of this preliminary data, no subsequent alterations were deemed necessary.

The questionnaire was distributed to all consecutive patients/decision makers who were about to have their first orthodontic appointment and who had agreed to participate. Data collection was performed between January and June 2018. 


\section{Statistical analysis}

Descriptive statistics were calculated for all variables, including means and standard deviations for continuous variables or absolute and relative frequencies for categorical variables. Binary logistic regressions were performed, after checking for possible violations of assumptions, to identify predictors for the response to a handful of selected questions of interest to the patient and/or the orthodontist (Supplementary Table 1). Each independent variable was initially added in a univariable model with the question response as dependent variable and all collected participant demographical / socio-cultural characteristics as independent variables. Subsequently, a multivariable model was built and all independent variables with $P \leq 0.20$ from the first model were added to account for confounders. All results are reported as Odds Ratios (OR) with their corresponding 95\% Confidence Intervals (Cl). Statistical significance was set to a two-sided $p$-value $(p) \leq 0.05$ and all analyses were run in Stata 14.1 (StataCorp, College Station, Texas).

\section{Results}

A total of 227 questionnaires were distributed to prospective orthodontic patients, of which 220 were filled out and returned (return rate of $96.9 \%$ on participant level). Not every question was answered by the participants as instructed, and therefore the number of the evaluated answers to each specific question varied from 198 to 218 of the total 227 (Supplementary Table 2). The final response rate at question level ranged correspondingly from $87.2 \%$ to $96.0 \%$.

The characteristics of the included patients or their guardians can be seen in Table 1. The mean age of the 220 participants was 37.1 years with a standard deviation of 11.9 years and a range of 16.0-68.0 years. The majority were female $(62.7 \%)$, of Swiss nationality $(74.8 \%)$, had a close family member with previous experience of orthodontic treatment $(62.2 \%)$, and reached out for an orthodontic consultation from their own initiative $(56.3 \%)$.

The participants' level of knowledge on post-orthodontic retention is given in Table 2. Less than half of the participants (46.3\%) were aware that retention appliances are used after orthodontic treatment. Only $32.6 \%$ of the participants thought that retention was necessary in all and not in specific cases only. 
Finally, the majority believed both that a perfect orthodontic result can guarantee the results' stability $(52.8 \%)$ and that teeth can also move on their own without any orthodontic appliances $(77.8 \%)$.

As far as expectations of the participants towards orthodontic retention are concerned (Table 3 ), only $12.7 \%$ thought that the retention phase should be less than one year, $38.5 \%$ thought that it should last between 1 and 3 years, and the remaining $48.8 \%$ believed it should extend over 3 to 10 years or lifelong. The vast majority of participants $(94.5 \%)$ rated the stability of the orthodontic results as 'rather important' or 'extremely important', while most of them (67.2\%) preferred a bonded retainer over a removable retention appliance. Most participants considered recalls were needed at 3-6 months' intervals $(57.7 \%)$ or once a year $(31.0 \%)$. The majority considered that the person most responsible for post-orthodontic stability was the orthodontist, followed by themselves, and finally the general dentist (with percentages being $73.2 \%$, $50.0 \%$, and $25.0 \%$, respectively - with overlap). Finally, the vast majority of the participants agreed that it is appropriate to charge fees for recall visits needed during orthodontic retention $(72.9 \%)$.

Responses to the questionnaire were considerably affected by the participants' demographics and socio-cultural traits, as can be seen in the multivariable analyses given in Table 4 (after variable selection in Supplementary Tables 3a-3f). Firstly, the odds of knowing that retention appliances are needed after orthodontic treatment were higher in participants with past orthodontic experience in close family members (OR: $2.1 ; 95 \% \mathrm{Cl}: 1.1-3.9$ ). Conversely, the odds of believing that a perfect orthodontic result can guarantee stability were lower for participants with middle or higher education (OR: $0.3 ; 95 \% \mathrm{Cl}: 0.2-0.8$ and OR: 0.2; $95 \% \mathrm{Cl}: 0.1-0.4)$. The odds of agreeing to lifelong retention were higher in Swiss participants (OR: $2.4 ; 95 \%$

$\mathrm{Cl}$ : 1.1-5.5). Additionally, the odds of believing that teeth can also move on their own without any orthodontic appliances were higher in younger participants, participants with middle or higher education, and participants with past orthodontic experiences in close relatives (Table 4). Finally, the odds of agreeing to be charged for retention recall visits were higher in female participants and those with middle or higher education (OR: $0.4 ; 95 \% \mathrm{Cl}: 0.2-0.8$ and OR: $4.6 ; 95 \% \mathrm{Cl}: 1.8-11.7)$.

\section{Discussion}

This study seems to be the first attempt to empirically assess the level of knowledge and the expectations of people deciding about a prospective orthodontic treatment regarding post-orthodontic retention. We 
considered it to be of high interest to target people who are in charge of deciding about an impending orthodontic treatment involving a prolonged retention protocol, and to identify what they know and what they expect - precisely at the time of their consent to the forthcoming treatment.

Although the number of participants and the return rate in this investigation can be considered sufficient to allow statistical tests beyond simple descriptive statistics, it was decided to refrain from a hypothesis-driven approach and remain entirely observational.

\section{Level of knowledge}

One of the most striking findings of the present study was that less than half of prospective patients or their guardians (46.3\%) were aware that retention appliances are used after orthodontic treatment (Table 2). Given the fact that almost all orthodontic patients are subject to some kind of retention protocol (6), and considering the finding that post-treatment stability is viewed as important or extremely important $(94.5 \%$; Table 3), this survey discloses an obvious divergence between the participants' anticipations and clinical reality. A previously treated close family member is a factor that seems to increase awareness of posttreatment retention need (OR: 2.1; Table 4), yet even when considering this influence, many participants remained unconscious of a need of retention appliances.

A second major observation is another dissonance in the participants' understanding of tooth movement and stability. While the majority of the participants $(77.8 \%)$ rightfully acknowledged that teeth can move without any orthodontic force, most also believed that a perfect result can guarantee stability per se and only $14.9 \%$ assumed that retention appliances are needed in all cases. The trained orthodontist appreciates that continuous tooth migration throughout adolescent and even adult life affects both occlusion and alignment (24-27), and may therefore ultimately compromise the stability of the achieved orthodontic results $(3,28,29)$. This study bears proof that this understanding is also shared by those participants with a higher level of education. Yet, for the majority of the population, non-orthodontic tooth movement is apparently not intuitive. Thus, this knowledge has to be transmitted, at the very latest before retention appliances are discontinued. The lack of knowledge concerning tooth migration seems especially acute with regard to orthodontics in adults, for which only $13.2 \%$ of the participants believed it was necessary to retain the achieved orthodontic result. Logistic regression models revealed that several socio-cultural 
factors, such as age, past experience of orthodontics within the family or the level of education, all had a significant impact on the understanding of tooth movement and stability. But these influences remained mostly moderate, with the exception of the aforementioned level of education.

Recent surveys identified that orthodontists, at least in Switzerland, tend towards a ubiquitous approach in their retention protocol, retaining all post-orthodontic patients $(13,15)$. This present investigation demonstrates that prospective patients are persuaded that only a minority of patients are in need of retention devices. Based on this observation, an obvious need of patient education becomes apparent.

\section{Expectations}

Patients' overall satisfaction with their orthodontic experience is intricately linked to their expectation of stability (22). A deeper understanding of particular expectations may therefore help avoid future dissatisfaction.

Overall, this study revealed that while the majority of the participants considered a stable result very important, an evident diversity in opinions and expectations exists concerning retention duration, recall intervals or preferred devices.

According to this survey two thirds of the participants preferred bonded retainers over removable devices, but no socio-cultural variables that might influence the choice were identified.

As far as expectations and preferences regarding orthodontic retention time are concerned, only one third of prospective orthodontic patients or their guardians expected lifelong retention, and the majority anticipated a retention phase of somewhere between 1 and 10 years. No evidence-basis exists on the optimal duration of retention, and the extent of the retention period is mostly up to the discretion of the orthodontist $(13,17)$. Screening the contemporary literature, a trend towards lifelong retention can be observed. This development has, however, major implications for patients apropos the number of recall visits and the demands made on their level of compliance. Based on the findings of this present survey that most prospective patients do not expect lifelong retention to be de rigueur, patients should be informed of the risk that some relapse will occur after removal of retention appliances and of the physiological adaptations that take place over time (22). The lack of evidence and the absence of binding protocols on 
retention duration or recall intervals $(8,10,13,15,17)$ accentuates the point that orthodontists must not adopt a paternalistic approach on that matter, but rather seek to involve the patient in the decision-making process vis-à-vis termination or prolongation of the retention phase.

Lifelong retention will not only increase demands on the contributory role of patients, but results in an intensified involvement of general dentists $(13,14)$. This study reveals that only $25 \%$ of the participants consider general practitioners to have any responsibility in the maintenance of retention devices. Prolonged retention should however be based on an involvement or at least a well-functioning communication and collaboration with general dentists $(13,15)$. Why Swiss participants were more likely to prefer lifelong retention remains open for interpretation.

On a positive note, this survey indicates that while for nearly all participants $(94.5 \%)$ a stable result was "rather important" or "extremely important", most were also ready to assume a certain degree of financial commitment and personal responsibility to guarantee a stable outcome. The majority (87.3\%) were ready to accept a retention phase of at least one year, most in fact expecting the duration to last much longer. Nearly all participants found recall intervals of 3 to 12 months acceptable, and $73 \%$ were prepared to pay for these recall visits. Although only $50 \%$ explicitly specified in their answers that they viewed the patient to be responsible for the stability after orthodontic treatment, the overall results bear witness that tparticipants are willing to accept a certain degree of commitment. While prospective patients or their guardians place the onus to guarantee a stable result on the orthodontists, they also realise that maintenance is necessary and can only be achieved with compliance. These observations indicate that the orthodontist is likely to find willing partners in post-orthodontic patients to contribute towards a successful retention phase. Somewhat surprisingly, females and participants with higher educational background were more likely to be willing to pay for recall visits. These findings are difficult to interpret, but are in line with a previous investigation indicating that people with higher education are more likely to be willing to pay more for health care services (30); and are in agreement with past observations that women tend to behave more generously (31) and more pro-socially than men in pecuniary matters (32).

\section{Limitations}


This study seems to be the first attempt to describe the level of knowledge and the expectations of prospective orthodontic patients or their parents/those with legal decision making responsibility, regarding post-orthodontic retention prior to any orthodontic appointment, is evidently not free of drawbacks. Firstly, this study reports the results of a single-centred survey in a university setting of a specific country. Thus, the observations are not necessarily generalisable across different countries and clinical settings. Some participants might have been informed prior to their first orthodontic appointment about the need of orthodontic retention appliances by friends, family members, or other information sources, which might have influenced their answers in this survey. Moreover, the decision to direct the questionnaire to parents and legal guardians in case the patient was younger than 16 years might also be criticised as arbitrary.

Lastly, some methodological shortcomings have to be addressed: open-ended questions could have yielded answers containing more information, but would have been more difficult to interpret statistically. While the limited amount of questions unquestionably aided to achieve a high return rate, it surely restricted to horizon of this survey.

Based on all these limitations, this piece of research should therefore be seen merely as an initial contribution to address the perspective of prospective patients regarding orthodontic retention. Mindful of all shortcomings, this study nevertheless identifies the necessity to further investigate pertinent issues related to pre-treatment expectations towards orthodontic retention, and highlight certain aspects which thitherto remained unnoticed.

\section{Conclusions}

This questionnaire-based survey reveals that guaranteeing the result of orthodontic treatment is of great importance to people deciding about a prospective orthodontic treatment. Knowledge regarding possible post-orthodontic relapse and the need for post-orthodontic retention varies, and seems to be influenced by socio-cultural factors. A certain consensus amongst Swiss prospective orthodontic patients I decision makers seems to exist regarding responsibility, necessity of recalls, the takeover of costs, and preferences in retainer devices. Based on the discussed results it appears mandatory to adequately inform prospective orthodontic patients about the need of post-orthodontic retention, and the extent of future commitment expected from them during the retention phase. 


\section{Conflict of interest}

The authors declare that they have no conflict of interest. 


\section{REFERENCES}

1. Kaplan, H. (1988) The logic of modern retention procedures. American journal of orthodontics and dentofacial orthopedics, 93, 325-340.

2. Little, R.M. (1990) Stability and relapse of dental arch alignment. British journal of orthodontics, $17,235-41$.

3. Little, R.M., Riedel, R.A. and Artun, J. (1988) An evaluation of changes in mandibular anterior alignment from 10 to 20 years postretention. American journal of orthodontics and dentofacial orthopedics, 93, 423-8.

4. Blake, M. and Bibby, K. (1998) Retention and stability: a review of the literature. American journal of orthodontics and dentofacial orthopedics, 114, 299-306.

5. Andriekute, A., Vasiliauskas, A. and Sidlauskas, A. (2017) A survey of protocols and trends in orthodontic retention. Progress in orthodontics, 18, 31.

6. Littlewood, S.J., Millett, D.T., Doubleday, B., Bearn, D.R. and Worthington, H.V. (2016) Retention procedures for stabilising tooth position after treatment with orthodontic braces. The cochrane database of systematic reviews, CD002283.

7. Wong, P.M. and Freer, T.J. (2004) A comprehensive survey of retention procedures in Australia and New Zealand. Australian orthodontic journal, 20, 99-106.

8. Meade, M.J. and Millett, D. (2013) Retention protocols and use of vacuum-formed retainers among specialist orthodontists. Journal of orthodontics, 40, 318-325.

9. Ab Rahman, N., Low, T.F. and Idris, N.S. (2016) A survey on retention practice among orthodontists in Malaysia. Korean journal of orthodontics, 46, 36-41.

10. Renkema, A.M., Sips, E.T., Bronkhorst, E. and Kuijpers-Jagtman, A.M. (2009) A survey on orthodontic retention procedures in The Netherlands. European journal of orthodontics, 31, $432-7$.

11. Padmos, J.A.D., Fudalej, P.S. and Renkema, A.M. (2018) Epidemiologic study of orthodontic retention procedures. American Journal of Orthodontics and Dentofacial Orthopedics, 153, 496504. 
12. Al-Jewair, T.S., Hamidaddin, M.A., Alotaibi, H.M., Alqahtani, N.D., Albarakati, S.F., Alkofide, E.A. and Al-Moammar, K.A. (2016) Retention practices and factors affecting retainer choice among orthodontists in Saudi Arabia. Saudi medical journal, 37, 895-901.

13. Arnold, S.N., Pandis, N. and Patcas, R. (2014) Factors influencing fixed retention practices in German-speaking Switzerland: A survey. Journal of orofacial orthopedics, 75, 446-58.

14. Habegger, M., Renkema, A.M., Bronkhorst, E., Fudalej, P.S. and Katsaros, C. (2017) A survey of general dentists regarding orthodontic retention procedures. European journal of orthodontics, 39, 69-75.

15. Lai, C.S., Grossen, J.M., Renkema, A.M., Bronkhorst, E., Fudalej, P.S. and Katsaros, C. (2014) Orthodontic retention procedures in Switzerland. Swiss dental journal, 124, 655-61.

16. Singh, P., Grammati, S. and Kirschen, R. (2009) Orthodontic retention patterns in the United Kingdom. Journal of orthodontics, 36, 115-21.

17. Bibona, K., Shroff, B., Best, A.M. and Lindauer, S.J. (2014) Factors affecting orthodontists' management of the retention phase. The Angle orthodontist, 84, 225-30.

18. Valiathan, M. and Hughes, E. (2010) Results of a survey-based study to identify common retention practices in the United States. American journal of orthodontics and dentofacial orthopedics, 137, 170-7; discussion 177.

19. Pratt, M.C., Kluemper, G.T., Hartsfield, J.K., Jr., Fardo, D. and Nash, D.A. (2011) Evaluation of retention protocols among members of the American Association of Orthodontists in the United States. American journal of orthodontics and dentofacial orthopedics, 140, 520-526.

20. Vandevska-Radunovic, V., Espeland, L. and Stenvik, A. (2013) Retention: type, duration and need for common guidelines. A survey of Norwegian orthodontists. Orthodontics : the art and practice of dentofacial enhancement, 14, e110-7.

21. Yao, J., Li, D.-D., Yang, Y.-Q., McGrath, C.P.J. and Mattheos, N. (2016) What are patients' expectations of orthodontic treatment: a systematic review. BMC oral health, 16, 19-19.

22. Mollov, N.D., Lindauer, S.J., Best, A.M., Shroff, B. and Tufekci, E. (2010) Patient attitudes toward retention and perceptions of treatment success. The Angle orthodontist, 80, 656-661. 
23. Swiss Academy of Medical Sciences. (2018) Assessment of capacity in medical practice. In: Medical-ethical guidelines, page 20. Berne, Switzerland.

24. Papageorgiou, S.N., Eliades, T. and Hammerle, C.H.F. (2018) Frequency of infraposition and missing contact points in implant-supported restorations within natural dentitions over time: A systematic review with meta-analysis. Clinical oral implants research, 29 Suppl 18, 309-325.

25. Thilander, B., Odman, J. and Lekholm, U. (2001) Orthodontic aspects of the use of oral implants in adolescents: a 10-year follow-up study. European journal of orthodontics, 23, 715-31.

26. Henrikson, J., Persson, M. and Thilander, B. (2001) Long-term stability of dental arch form in normal occlusion from 13 to 31 years of age. European journal of orthodontics, 23, 51-61.

27. Thilander, B. (2009) Dentoalveolar development in subjects with normal occlusion. A longitudinal study between the ages of 5 and 31 years. European journal of orthodontics, 31, 109-20.

28. Kahl-Nieke, B., Fischbach, H. and Schwarze, C.W. (1995) Post-retention crowding and incisor irregularity: a long-term follow-up evaluation of stability and relapse. British journal of orthodontics, 22, 249-57.

29. Little, R.M. (1999) Stability and relapse of mandibular anterior alignment: University of Washington studies. Seminars in orthodontics, 5, 191-204.

30. Pavel, M.S., Chakrabarty, S. and Gow, J. (2015) Assessing willingness to pay for health care quality improvements. BMC health services research, 15, 43-43.

31. Furnham, A., von Stumm, S. and Fenton-O'Creevy, M. (2015) Sex Differences in Money Pathology in the General Population. Social indicators research, 123, 701-711.

32. Soutschek, A., Burke, C.J., Raja Beharelle, A., Schreiber, R., Weber, S.C., Karipidis, I.I., ten Velden, J., Weber, B., Haker, H., Kalenscher, T. and Tobler, P.N. (2017) The dopaminergic reward system underpins gender differences in social preferences. Nature Human Behaviour, 1, 819-827. 


\section{TABLES}

Table 1. Demographics of participants returning questionnaires $(n=220)$

Age: mean 37.1 years; SD 11.9 years; range $16.0-68.0$ years

\begin{tabular}{|c|c|c|c|}
\hline & & $\mathrm{N}$ & $\%$ \\
\hline \multirow[t]{2}{*}{$\operatorname{Sex}\left(\mathrm{Na}_{\mathrm{a}}=217\right)$} & Females & 136 & $62.7 \%$ \\
\hline & Males & 81 & $37.3 \%$ \\
\hline \multirow[t]{7}{*}{ Nationality $\left(\mathrm{N}_{\mathrm{a}}=218\right)$} & Swiss & 163 & $74.8 \%$ \\
\hline & Western Europe & 30 & $13.8 \%$ \\
\hline & Eastern Europe Russia & 8 & $3.7 \%$ \\
\hline & North America & 2 & $0.9 \%$ \\
\hline & Latin America & 3 & $1.4 \%$ \\
\hline & Asia & 8 & $3.7 \%$ \\
\hline & Africa \& Middle East & 4 & $1.8 \%$ \\
\hline \multirow[t]{5}{*}{ Education $\left(\mathrm{N}_{\mathrm{a}}=201\right)$} & Basic education & 51 & $25.4 \%$ \\
\hline & $\begin{array}{l}\text { Completed } \\
\text { Apprenticeship }\end{array}$ & 64 & $31.8 \%$ \\
\hline & A-Level equivalent & 14 & $7.0 \%$ \\
\hline & $\begin{array}{l}\text { College or higher } \\
\text { education }\end{array}$ & 30 & $14.9 \%$ \\
\hline & University & 42 & $20.9 \%$ \\
\hline \multirow[t]{2}{*}{$\begin{array}{l}\text { Previous experiences with orthodontics } \\
\text { within close family }\left(\mathrm{N}_{a}=217\right)\end{array}$} & No & 82 & $37.8 \%$ \\
\hline & Yes & 135 & $62.2 \%$ \\
\hline \multirow[t]{2}{*}{ Reason of consultation $\left(\mathrm{N}_{\mathrm{a}}=217\right)$} & Self-motivated & 121 & $56.3 \%$ \\
\hline & Referral & 94 & $43.7 \%$ \\
\hline \multirow[t]{2}{*}{ Clinic $\left(\mathrm{N}_{\mathrm{a}}=206\right)$} & Postgraduate Clinic & 143 & $69.4 \%$ \\
\hline & Clinic of Senior Staff & 63 & $30.6 \%$ \\
\hline
\end{tabular}

$\mathrm{Na}$, number of questionnaires returned and having answered each specific question; $\mathrm{N}$, number of questionnaires with this specific answer. 
Table 2. Participants' level of knowledge.

\begin{tabular}{|c|c|c|c|}
\hline 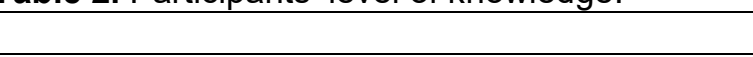 & & $\mathrm{N}$ & $\%$ \\
\hline \multirow[t]{2}{*}{$\begin{array}{l}\text { "Are you aware that appliances are used for } \\
\text { retention after orthodontic treatment?" }\left(\mathrm{N}_{a}=214\right)\end{array}$} & Yes & 99 & $46.3 \%$ \\
\hline & No & 115 & $53.7 \%$ \\
\hline \multirow[t]{4}{*}{$\begin{array}{l}\text { "How often do you think such appliances are } \\
\text { necessary?" }\left(\mathrm{N}_{a}=208\right)\end{array}$} & In rare cases & 24 & $11.5 \%$ \\
\hline & In half the cases & 50 & $24.0 \%$ \\
\hline & In most cases & 103 & $49.5 \%$ \\
\hline & In all cases & 31 & $14.9 \%$ \\
\hline \multirow[t]{5}{*}{$\begin{array}{l}\text { "In which cases do you consider retention } \\
\text { necessary?" }\left(\mathrm{N}_{\mathrm{a}}=206\right)^{*}\end{array}$} & $\begin{array}{l}\text { After comprehensive } \\
\text { tooth movement }\end{array}$ & 98 & $46.2 \%$ \\
\hline & $\begin{array}{l}\text { After treatment with } \\
\text { extractions }\end{array}$ & 54 & $25.5 \%$ \\
\hline & $\begin{array}{l}\text { After treatment during } \\
\text { growth }\end{array}$ & 92 & $43.4 \%$ \\
\hline & After treatment in adults & 28 & $13.2 \%$ \\
\hline & In all cases & 69 & $32.6 \%$ \\
\hline \multirow[t]{2}{*}{$\begin{array}{l}\text { "Do you believe a perfect treatment result can } \\
\text { guarantee stability?" }\left(\mathrm{N}_{\mathrm{a}}=214\right)\end{array}$} & Yes & 113 & $52.8 \%$ \\
\hline & No & 101 & $47.2 \%$ \\
\hline \multirow[t]{2}{*}{$\begin{array}{l}\text { "Do you think that teeth can also move without } \\
\text { orthodontic appliances?" }\left(\mathrm{N}_{\mathrm{a}}=216\right)\end{array}$} & Yes & 168 & $77.8 \%$ \\
\hline & No & 48 & $22.2 \%$ \\
\hline
\end{tabular}

$\mathrm{N}_{\mathrm{a}}$, number of questionnaires returned and having answered each specific question; N, number of questionnaires with this specific answer.

${ }^{*}$ more than one answer possible, so the summary $\%$ adds to more than $100 \%$ 
Table 3. Participants' expectations in orthodontic retention.

\begin{tabular}{|c|c|c|c|}
\hline & & $\mathrm{N}$ & $\%$ \\
\hline \multirow[t]{4}{*}{$\begin{array}{l}\text { "How long do you think should the retention phase be?" } \\
\left(\mathrm{N}_{a}=213\right)\end{array}$} & $<1$ year & 27 & $12.7 \%$ \\
\hline & $1-3$ years & 82 & $38.5 \%$ \\
\hline & $3-10$ years & 33 & $15.5 \%$ \\
\hline & Lifelong & 71 & $33.3 \%$ \\
\hline \multirow[t]{4}{*}{ "How important is a stable result for you?" $\left(\mathrm{N}_{a}=218\right)$} & Not important & 1 & $0.5 \%$ \\
\hline & Ambivalent & 11 & $5.1 \%$ \\
\hline & $\begin{array}{l}\text { Rather } \\
\text { important }\end{array}$ & 47 & $21.6 \%$ \\
\hline & $\begin{array}{l}\text { Extremely } \\
\text { important }\end{array}$ & 159 & $72.9 \%$ \\
\hline \multirow[t]{2}{*}{ "Which type of retention device would you favour?" $\left(\mathrm{N}_{a}=198\right)$} & $\begin{array}{l}\text { Removable } \\
\text { device }\end{array}$ & 65 & $32.8 \%$ \\
\hline & Bonded device & 133 & $67.2 \%$ \\
\hline \multirow[t]{5}{*}{$\begin{array}{l}\text { "At which interval do you believe is a recall necessary?" } \\
\left(N_{a}=213\right)\end{array}$} & Every $3 \mathrm{Mt}$ & 65 & $30.5 \%$ \\
\hline & Every $6 \mathrm{Mt}$ & 58 & $27.2 \%$ \\
\hline & Yearly & 66 & $31.0 \%$ \\
\hline & Every $2^{\text {nd }}$ year & 13 & $6.1 \%$ \\
\hline & Every $5^{\text {th }}$ year & 11 & $5.2 \%$ \\
\hline \multirow[t]{3}{*}{$\begin{array}{l}\text { "Who do you consider responsible for the stability after } \\
\text { orthodontic treatment?" }\left(\mathrm{N}_{a}=210\right)^{*}\end{array}$} & $\begin{array}{l}\text { Patient and/or } \\
\text { parent }\end{array}$ & 108 & $50.0 \%$ \\
\hline & General dentist & 54 & $25.0 \%$ \\
\hline & Orthodontist & 158 & $73.2 \%$ \\
\hline \multirow[t]{2}{*}{$\begin{array}{l}\text { "Do you think it is appropriate to charge for recall visits?" } \\
\left(\mathrm{N}_{a}=210\right)\end{array}$} & Yes & 153 & $72.9 \%$ \\
\hline & No & 57 & $27.1 \%$ \\
\hline
\end{tabular}

$\mathrm{Na}$, number of questionnaires returned and having answered each specific question; $\mathrm{N}$, number of questionnaires with this specific answer.

${ }^{*}$ more than one answer possible, so the summary $\%$ adds to more than $100 \%$ 
Table 4. Summary of statistically significant predictors of answers to selected questions after univariable/multivariable binary logistic regression (see Supplementary Tables 3a-3f).

\begin{tabular}{|c|c|c|c|c|c|c|c|}
\hline The participant... & $\operatorname{Sex}^{1}$ & $\mathrm{Age}^{2}$ & Education $^{3}$ & Education $^{4}$ & Nationality ${ }^{5}$ & $\begin{array}{l}\text { Past } \\
\text { experiences }\end{array}$ & What happens? \\
\hline & $\begin{array}{l}\text { OR } \\
(95 \% \mathrm{Cl})\end{array}$ & $\begin{array}{l}\text { OR } \\
(95 \% \mathrm{Cl})\end{array}$ & $\begin{array}{l}\text { OR } \\
(95 \% \mathrm{Cl})\end{array}$ & $\begin{array}{l}\text { OR } \\
(95 \% \mathrm{Cl})\end{array}$ & $\begin{array}{l}\text { OR } \\
(95 \% \mathrm{Cl})\end{array}$ & $\begin{array}{l}\text { OR } \\
(95 \% \mathrm{Cl})\end{array}$ & \\
\hline $\begin{array}{l}\text {...is aware retention devices are } \\
\text { being used after orthodontic } \\
\text { treatment }\end{array}$ & NS & NS & NS & NS & NS & $\begin{array}{l}2.10 \\
(1.14-3.87)\end{array}$ & $\begin{array}{l}\text { Participants with past } \\
\text { orthodontic experience within } \\
\text { close family are more likely to } \\
\text { know retention devices are } \\
\text { being used after orthodontic } \\
\text { treatment }\end{array}$ \\
\hline $\begin{array}{l}\ldots \text { believes a perfect result } \\
\text { guarantees stability }\end{array}$ & NS & NS & $\begin{array}{l}0.34 \\
(0.15-0.77)\end{array}$ & $\begin{array}{l}0.17 \\
(0.07-0.39)\end{array}$ & NS & NS & $\begin{array}{l}\text { Participants with middle or } \\
\text { higher education are less likely } \\
\text { to believe a perfect result } \\
\text { guarantees stability }\end{array}$ \\
\hline $\begin{array}{l}\text {...thinks the retention phase } \\
\text { should be lifelong }\end{array}$ & NS & NS & NS & NS & $\begin{array}{l}2.44 \\
(1.08-5.50)\end{array}$ & NS & $\begin{array}{l}\text { Swiss participants are more } \\
\text { likely to think the retention } \\
\text { phase should be lifelong }\end{array}$ \\
\hline $\begin{array}{l}\text {...thinks teeth can move without } \\
\text { orthodontics }\end{array}$ & NS & $\begin{array}{l}0.96 \\
(0.93-0.99)\end{array}$ & $\begin{array}{l}3.09 \\
(1.33-7.20)\end{array}$ & $\begin{array}{l}7.80 \\
(2.75-22.12)\end{array}$ & NS & $\begin{array}{l}2.84 \\
(1.34-5.99)\end{array}$ & $\begin{array}{l}\text { Younger participants, } \\
\text { participants with middle or } \\
\text { higher education, and } \\
\text { participants with past } \\
\text { orthodontic experience are } \\
\text { more likely to think teeth can } \\
\text { move without orthodontics }\end{array}$ \\
\hline $\begin{array}{l}\text {...favours removable over fixed } \\
\text { retainer }\end{array}$ & NS & NS & NS & NS & NS & NS & - \\
\hline $\begin{array}{l}\text {...believes it is appropriate to } \\
\text { charge for recall visits }\end{array}$ & $\begin{array}{l}0.39 \\
(0.20-0.77)\end{array}$ & NS & NS & $\begin{array}{l}4.64 \\
(1.84-11.70)\end{array}$ & NS & NS & $\begin{array}{l}\text { Female participants and } \\
\text { participants with higher } \\
\text { education are more likely to } \\
\text { believe it is appropriate to } \\
\text { charge for recall visits }\end{array}$ \\
\hline
\end{tabular}

\section{NS, not significant at $5 \%$.}

${ }^{1}$ Female (reference) compared to male

${ }^{2}$ per additional year

${ }^{3}$ Basic education (reference) compared to apprenticeship / A level equivalent

${ }^{4}$ Basic education (reference) compared to college/university

${ }^{5}$ Non-Swiss (reference) compared to Swiss

${ }^{6}$ No previous experience (reference) compared to past experiences with orthodontics in own close family 


\section{Supplementary Material}

Supplementary Table 1. Selected questions out of the questionnaire to assess predictors for giving a specific answer through logistic regression. No. Question

$1 \quad$ Are you aware that appliances are used for retention after orthodontic treatment?

2 Do you believe a perfect result can guarantee a stable result?

3 Do you think that teeth can also move without orthodontic appliances? Answer

$4 \quad$ How long do you think should the retention phase be?

5 Which type of retention device would you favour?

\begin{tabular}{l|l}
\hline 6 & Do you think it is appropriate to charge for recall visits?
\end{tabular}

"Yes"

"Yes"

"Yes"

"Lifelong"

"Bonded"

"Yes"


Supplementary Table 2. Return and response rate for the administered questionnaires.

\begin{tabular}{|c|c|c|c|}
\hline & & $\mathrm{N}$ & $\%$ \\
\hline \multicolumn{4}{|l|}{ A. Return rate } \\
\hline & Administered & 227 & $100.0 \%$ \\
\hline & Returned & 220 & $96.9 \%$ \\
\hline \multicolumn{4}{|l|}{ B. Response rate } \\
\hline \multicolumn{4}{|l|}{ B1. Demographics } \\
\hline \multirow[t]{2}{*}{ Sex } & Answered & 197 & $98.6 \%$ \\
\hline & Missing & 3 & $1.4 \%$ \\
\hline \multirow[t]{2}{*}{ Nationality } & Answered & 218 & $99.1 \%$ \\
\hline & Missing & 2 & $0.9 \%$ \\
\hline \multirow[t]{2}{*}{ Education } & Answered & 201 & $91.4 \%$ \\
\hline & Missing & 19 & $8.6 \%$ \\
\hline \multirow[t]{2}{*}{ Previous experiences with orthodontics within close family } & Answered & 217 & $98.6 \%$ \\
\hline & Missing & 3 & $1.4 \%$ \\
\hline \multirow[t]{2}{*}{ Reason of consultation } & Answered & 215 & $97.7 \%$ \\
\hline & Missing & 5 & $2.3 \%$ \\
\hline \multirow[t]{2}{*}{ Clinic } & Answered & 206 & $93.6 \%$ \\
\hline & Missing & 14 & $6.4 \%$ \\
\hline \multicolumn{4}{|l|}{ B2. Participants' level of knowledge } \\
\hline \multirow{2}{*}{ "Are you aware that appliances are used for retention after orthodontic treatment?" } & Answered & 214 & $97.3 \%$ \\
\hline & Missing & 6 & $2.7 \%$ \\
\hline \multirow[t]{2}{*}{ "How often do you think such appliances are necessary?" } & Answered & 208 & $94.5 \%$ \\
\hline & Missing & 12 & $5.5 \%$ \\
\hline \multirow{2}{*}{$\begin{array}{l}\text { "In which cases do you consider retention necessary?" } \\
-\end{array}$} & Answered & 212 & $96.4 \%$ \\
\hline & Missing & 8 & $3.6 \%$ \\
\hline \multirow[t]{2}{*}{ "Do you believe a perfect result can guarantee a stable result"? } & Answered & 214 & $97.3 \%$ \\
\hline & Missing & 6 & $2.7 \%$ \\
\hline \multirow[t]{2}{*}{ "Do you think that teeth can also move without orthodontic appliances?" } & Answered & 216 & $98.2 \%$ \\
\hline & Missing & 4 & $1.8 \%$ \\
\hline \multicolumn{4}{|l|}{ B3. Participants' expectations in orthodontic retention } \\
\hline \multirow[t]{2}{*}{ "How long do you think should the retention phase be?" } & Answered & 213 & $96.8 \%$ \\
\hline & Missing & 7 & $3.2 \%$ \\
\hline \multirow[t]{2}{*}{ "How important is a stable is result for you?" } & Answered & 218 & $99 . \%$ \\
\hline & Missing & 2 & $0.9 \%$ \\
\hline \multirow[t]{2}{*}{ "Which type of retention device would you favour?" } & Answered & 198 & $90.0 \%$ \\
\hline & Missing & 22 & $10.0 \%$ \\
\hline \multirow[t]{2}{*}{ "At which interval do you believe is a recall necessary?" } & Answered & 213 & $96.8 \%$ \\
\hline & Missing & 7 & $3.2 \%$ \\
\hline \multirow[t]{2}{*}{ "Who do you consider responsible for the stability after orthodontic treatment?" } & Answered & 216 & $98.2 \%$ \\
\hline & Missing & 4 & $1.8 \%$ \\
\hline \multirow[t]{2}{*}{ "Do you think it is appropriate to charge for recall visits?" } & Answered & 210 & $95.5 \%$ \\
\hline & Missing & 10 & $4.5 \%$ \\
\hline
\end{tabular}


Supplementary Table 3a. Results of univariable and multivariable binary logistic regression on the question: "Are you aware that appliances are used for retention after orthodontic treatment?"

\begin{tabular}{|c|c|c|c|c|c|}
\hline 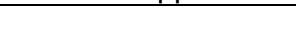 & & Univariable & & Multivariable & \\
\hline Factor & Category & OR (95\% Cl) & $\mathbf{P}$ & OR (95\% Cl) & $\mathbf{P}$ \\
\hline Age & Per year & $1.01(0.99-1.04)$ & 0.31 & NT & \\
\hline \multirow[t]{2}{*}{ Sex } & Female & Referent & & NT & \\
\hline & Male & $0.74(0.42-1.30)$ & 0.29 & NT & \\
\hline \multirow[t]{2}{*}{ Nationality } & Non-Swiss & Referent & & NT & \\
\hline & Swiss & $0.88(0.47-1.65)$ & 0.70 & NT & \\
\hline \multirow[t]{3}{*}{ Education } & Basic & Referent & & Referent & \\
\hline & Apprenticeship/A level & $1.09(0.53-2.24)$ & 0.83 & $1.01(0.48-2.12)$ & 0.98 \\
\hline & College/university & $1.74(0.83-3.62)$ & 0.14 & $1.57(0.74-3.34)$ & 0.24 \\
\hline \multirow[t]{2}{*}{ Previous experience } & No & Referent & & Referent & \\
\hline & Yes & $2.36(1.32-4.22)$ & 0.004 & $2.10(1.14-3.87)$ & 0.02 \\
\hline
\end{tabular}

Education and previous experience only slightly correlated $(r=0.14)$ so multicollinearity no problem.

$\mathrm{Cl}$, confidence interval; NT, not tested; OR, odds ratio.

Supplementary Table 3b. Results of univariable and multivariable binary logistic regression on the question: "Do you believe a perfect result can guarantee a stable result?"

\begin{tabular}{|l|l|l|l|l|l|}
\hline & & Univariable & & Multivariable & \\
\hline Factor & Category & OR (95\% CI) & P & OR (95\% CI) & P \\
\hline Age & Per year & $1.01(0.98-1.03)$ & 0.66 & NT & \\
\hline & & & & & \\
\hline Sex & Female & Referent & & Referent & \\
\hline & Male & $1.50(0.85-2.65)$ & 0.16 & $1.66(0.88-3.13)$ & 0.12 \\
\hline Nationality & & & & & \\
\hline & Non-Swiss & Referent & & NT & \\
\hline & Swiss & $0.77(0.41-1.44)$ & 0.41 & NT & \\
\hline Education & & & & & \\
\hline & Basic & Referent & & Referent & \\
\hline & Apprenticeship/A level & $0.36(0.16-0.79)$ & 0.01 & $0.34(0.15-0.77)$ & 0.01 \\
\hline & College/university & $0.18(0.08-0.41)$ & $<0.001$ & $0.17(0.07-0.39)$ & $<0.001$ \\
\hline Previous experience & No & & & & \\
\hline & Yes & Referent & & NT & NT \\
\hline
\end{tabular}

Sex and education not correlated.

$\mathrm{Cl}$, confidence interval; NT, not tested; OR, odds ratio.

Supplementary Table 3c. Results of univariable and multivariable binary logistic regression on the question: "How long do you think should the retention phase be?" with the answer being "lifelong".

\begin{tabular}{|c|c|c|c|c|c|}
\hline 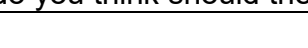 & 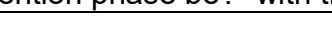 & Univariable & & Multivariable & \\
\hline Factor & Category & OR $(95 \% \mathrm{Cl})$ & $\mathbf{P}$ & OR $(95 \% \mathrm{Cl})$ & $\mathbf{P}$ \\
\hline Age & Per year & $0.97(0.95-1.00)$ & 0.03 & $0.97(0.94-1.00)$ & 0.07 \\
\hline \multirow[t]{2}{*}{ Sex } & Female & Referent & & NT & \\
\hline & Male & $1.03(0.57-1.85)$ & 0.93 & NT & \\
\hline \multirow[t]{2}{*}{ Nationality } & Non-Swiss & Referent & & Referent & \\
\hline & Swiss & $2.47(1.19-5.16)$ & 0.02 & $2.44(1.08-5.50)$ & 0.03 \\
\hline \multirow[t]{3}{*}{ Education } & Basic & Referent & & Referent & \\
\hline & Apprenticeship/A level & $1.91(0.87-4.16)$ & 0.11 & $2.00(0.89-4.51)$ & 0.10 \\
\hline & College/university & $1.33(0.59-3.01)$ & 0.49 & $1.57(0.65-3.80)$ & 0.32 \\
\hline \multirow[t]{2}{*}{ Previous experience } & No & Referent & & NT & \\
\hline & Yes & $1.20(0.66-2.19)$ & 0.55 & NT & \\
\hline
\end{tabular}

Among the three correlations of covariates (age, nationality, and education) only age and education correlate, but only slightly ( $r=0.25)$, so multicollinearity should be no problem.

$\mathrm{Cl}$, confidence interval; NT, not tested; OR, odds ratio. 
Supplementary Table 3d. Results of univariable and multivariable binary logistic regression on the question: "“Do you think that teeth can also move without orthodontic appliances?"

\begin{tabular}{|c|c|c|c|c|c|}
\hline 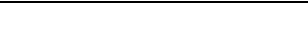 & & Univariable & & Multivariable & \\
\hline Factor & Category & OR (95\% Cl) & $\mathbf{P}$ & OR (95\% Cl) & $\mathbf{P}$ \\
\hline Age & Per year & $0.97(0.94-1.00)$ & 0.03 & $0.96(0.93-0.99)$ & 0.01 \\
\hline \multirow[t]{2}{*}{ Sex } & Female & Referent & & NT & \\
\hline & Male & $0.85(0.44-1.64)$ & 0.63 & NT & \\
\hline \multirow[t]{2}{*}{ Nationality } & Non-Swiss & Referent & & NT & \\
\hline & Swiss & $1.40(0.68-2.88)$ & 0.36 & NT & \\
\hline \multirow[t]{3}{*}{ Education } & Basic & Referent & & Referent & \\
\hline & Apprenticeship/A level & $2.94(1.33-6.53)$ & 0.008 & $3.09(1.33-7.20)$ & 0.009 \\
\hline & College/university & $6.62(2.53-17.31)$ & $<0.001$ & $7.80(2.75-22.12)$ & $<0.001$ \\
\hline \multirow[t]{2}{*}{ Previous experience } & No & Referent & & Referent & \\
\hline & Yes & $3.42(1.75-6.68)$ & $<0.001$ & $2.84(1.34-5.99)$ & 0.006 \\
\hline
\end{tabular}

Among the three correlations of covariates (age, nationality, and education) only age and education correlate, but only slightly $(r=0.25)$, so multicollinearity should be no problem.

$\mathrm{Cl}$, confidence interval; NT, not tested; OR, odds ratio.

Supplementary Table 3e. Results of univariable and multivariable binary logistic regression on the question: "Which type of retention device would you favour?" with the answer being "bonded".

\begin{tabular}{|l|l|l|l|l|l|}
\hline & & Univariable & & Multivariable \\
\hline Factor & Category & OR (95\% Cl) & P & OR (95\% CI) & P \\
\hline Age & Per year & $1.00(0.97-1.02)$ & 0.76 & NT & \\
\hline Sex & & & & & NT \\
\hline & Female & Referent & & NT & \\
\hline & Male & $1.02(0.55-1.89)$ & 0.95 & & \\
\hline Nationality & & & & NT & \\
\hline & Non-Swiss & Referent & & NT & \\
\hline Education & Swiss & $0.85(0.42-1.73)$ & 0.65 & & NT \\
\hline & & & & NT & \\
\hline & Basic & Referent & & NT \\
\hline Previous experience & Apprenticeship/A level & $1.14(0.53-2.48)$ & 0.73 & & \\
\hline & College/university & $1.61(0.71-3.66)$ & 0.25 & & \\
\hline
\end{tabular}

$\mathrm{Cl}$, confidence interval; NT, not tested; OR, odds ratio.

Supplementary Table 3f. Results of univariable and multivariable binary logistic regression on the question: "Do you think it is appropriate to charge for recall visits?"

\begin{tabular}{|l|l|l|l|l|l|}
\hline & & Univariable & & Multivariable \\
\hline Factor & Category & OR (95\% Cl) & P & OR (95\% Cl) & P \\
\hline Age & Per year & $1.02(1.00-1.05)$ & 0.09 & $1.01(0.98-1.04)$ \\
\hline & & & & & 0.36 \\
\hline Sex & Female & Referent & & Referent & \\
\hline & Male & $0.42(0.23-0.79)$ & 0.007 & $0.39(0.20-0.77)$ & 0.007 \\
\hline Nationality & & & & & \\
\hline & Non-Swiss & Referent & & NT & \\
\hline & Swiss & $0.74(0.36-1.54)$ & 0.42 & NT & \\
\hline Education & & & & & Referent \\
\hline & Basic & Referent & & & $1.82(0.84-3.96)$ \\
\hline & Apprenticeship/A level & $1.93(0.91-4.07)$ & 0.09 & 0.13 \\
\hline & College/university & $4.56(1.90-10.91)$ & 0.001 & $4.64(1.84-11.70)$ & 0.001 \\
\hline Previous experience & No & & & & \\
\hline & Yes & Referent & & NT \\
\hline
\end{tabular}

$\mathrm{Cl}$, confidence interval; NT, not tested; OR, odds ratio. 
